\title{
Associations between time spent in green areas and physical activity among late middle-aged adults
}

\author{
Bart Dewulf, ${ }^{1-3}$ Tijs Neutens, ${ }^{1,2}$ Delfien Van Dyck, ${ }^{2,4}$ Ilse de Bourdeaudhuij, ${ }^{4}$ \\ Steven Broekx, ${ }^{3}$ Carolien Beckx, ${ }^{3}$ Nico Van de Weghe ${ }^{1}$ \\ ${ }^{1}$ Department of Geography, Ghent University, Ghent; ${ }^{2}$ Research Foundation Flanders, \\ Brussels; ${ }^{3}$ Flemish Institute for Technological Research (VITO), Mol; ${ }^{4}$ Department of \\ Movement and Sport Sciences, Ghent University, Ghent, Belgium
}

\begin{abstract}
Physical activity is an important facilitator for health and wellbeing, especially for late middle-aged adults, who are more susceptible to cardiovascular diseases. Physical activity performed in green areas is supposed to be particularly beneficial, so we studied whether late middle-aged adults are more active in green areas than in non-green areas and how this is influenced by individual characteristics and the level of neighbourhood greenness. We tracked 180 late middle-aged (58 to 65 years) adults using global positioning system and accelerometer
\end{abstract}

Correspondence: Bart Dewulf, Department of Geography, Faculty of Sciences, Ghent University, Krijgslaan 281S8, B-9000 Ghent, Belgium. Tel: +32.9264 .4695$

E-mail: bartd.dewulf@ugent.be

Key words: Late middle-aged adults; GPS; Accelerometer; Physical activity; Greenness.

Contributions: BD carried out the main research and drafted the manuscript; TN, DVD, and SB participated in the study design and helped to draft the manuscript; NVdW, IdB, and CB coordinated the study. All authors reviewed the manuscript and approved the final version.

Conflict of interest: the authors declare no potential conflict of interest.

Funding: this research was supported by the Fund for Scientific Research Flanders (FWO) B/13230/01, Fund IV2.

Ethical approval: the study was approved by the Ethics Committee of the Ghent University Hospital (2012/716; Belgian registration number B670201215326). All participants provided consent before initiation of the data collection.

Received for publication: 18 September 2015.

Revision received: 15 February 2016.

Accepted for publication: 17 February 2016.

(C) Copyright B. Dewulf et al., 2016

Licensee PAGEPress, Italy

Geospatial Health 2016; 11:411

doi:10.4081/gh.2016.411

This article is distributed under the terms of the Creative Commons Attribution Noncommercial License (CC BY-NC 4.0) which permits any noncommercial use, distribution, and reproduction in any medium, provided the original author(s) and source are credited. data to know whether and where they were sedentary or active. These data were combined with information on land use to obtain information on the greenness of sedentary and active hotspots. We found that late middle-aged adults are more physically active when spending more time in green areas than in non-green areas. Spending more time at home and in non-green areas was found to be associated with more sedentary behaviour. Time spent in non-green areas was found to be related to more moderate-to-vigorous physical activity (MVPA) for males and to less MVPA for females. The positive association between time spent in green areas and MVPA was the strongest for highly educated people and for those living in a green neighbourhood. This study shows that the combined use of global positioning system and accelerometer data facilitates understanding of where people are sedentary or physically active, which can help policy makers encourage activity in this age cohort.

\section{Introduction}

Aging is often associated with physical frailty and increased health problems (Rockwood et al., 2004; Landi et al., 2010). With increasing life expectancy and an expected increased number of middle-aged (45 to 65 years) and older adults ( $\geq 65$ years) in the future, health care costs are expected to rise globally (Department of Health, 2004; OECD, 2006). Sufficient physical activity and limited sedentary behaviour can prevent certain diseases, especially in middle-aged and older adults, who are more susceptible to cardiovascular diseases than younger people (Warburton et al., 2006; Cavill et al., 2008; US Department of Health and Human Services, 2008; King and Guralnik, 2010; Warburton et al., 2006; Hamilton et al., 2012).

Theoretically, late middle-aged adults (58 to 65 years) have more leisure time to spend on recreational physical activity (PA) or active transport than younger adults and could thus be more physically active or spend more time away from home (Banister and Bowling, 2004). However, with increasing age people seem to spend more time at home (Kerr et al., 2012), their sedentary behaviour increases (Clark et al., 2014; Ortlieb et al., 2014), and they are less physically active (Bauman and Bull, 2007; Troiano et al., 2008; Ortlieb et al., 2014). In most developed countries, 60 to $70 \%$ of adults aged 65 and more do not reach 150 minutes of moderate-to-vigorous PA (MVPA) per week, which is recommended to benefit positive health effects (Centers for Disease and Control Prevention, 1996; WHO, 2010).

The presence of green areas can have a positive impact on achieving these health effects. Several publications demonstrate that a higher availability of accessible green spaces is associated with a higher amount of PA (Van Cauwenberg et al., 2011; Van Holle et al., 2012, 
2014). On the other hand, when PA occurs in green areas (e.g. parks; Coombes et al., 2013), it can have positive effects on both physical (e.g. less exposure to pollution) and mental (e.g. wellbeing) health (Frumkin, 2001; St Leger, 2003; Sugiyama et al., 2008; Mackay and Neill, 2010; Fan et al., 2011; Thompson et al., 2011). It has also been demonstrated that performing PA in non-green areas, especially alongside urban roads, increases inhalation levels and hence exposure to air pollution (Int Panis et al., 2010). Providing a sufficient amount of accessible green areas in urban areas is potentially a cost effective way to improve health and wellbeing. However, the relationships between greenness and health are complex and further exploration is needed. The research presented here explores the link between PA levels of late middle-aged adults and the presence of green areas. Not only do we focus on where PA mainly takes place as this significantly influences health impacts, but also on the general relationship between the amount of available greenness and the level of PA. To better understand time-activity patterns and PA of late middle-aged adults, it is important to know if and where they are mostly active. Global positioning system (GPS) devices in combination with accelerometers have been previously used to analyse the location-specific PA in children (Elgethun et al., 2003; Almanza et al., 2012; Lachowycz et al., 2012; Oreskovic et al., 2012; Coombes et al., 2013). Knowing where people are can give insights into their exposure to different attributes of the environment (e.g. air pollution, noise, greenness) and related health effects (Seeger et al., 2007; Dons et al., 2013; Bekö et al., 2015; Dewulf et al., 2016). Knowing where people are physically active (in terms of location or greenness) can also provide policy makers with insights into people's needs.

There are numerous factors influencing both PA itself and the association between greenness, location (i.e. at home, in the neighbourhood or further away) and PA, which need to be known to further promote PA. Several individual characteristics are correlates of PA. Males with a higher income and normal weight tend to be more physically active than their counterparts (Bauman and Bull, 2007; Ortlieb et al., 2014). For older adults, being confident to be physically active and having social support is positively correlated with PA, while feeling too old has an adverse effect (Bauman and Bull, 2007; Carlson et al., 2012). Next to individual characteristics, the relation of neighbourhood built environment factors and PA has been widely studied in the past, mainly showing that people living in highly walkable neighbourhoods tend to be more physically active (Berke et al., 2007; Frank et al., 2010; King et al., 2011; Marshall et al., 2014; Van Holle et al., 2014; Marquet and Miralles-Guasch, 2015). However, a study based on a national survey on Canadian adults reports that there is a positive association between neighbourhood greenness in a $500 \mathrm{~m}$ buffer around the home location and leisure-time PA (McMorris et al., 2015). Research on the influence of greenness on PA in late middle-aged adults is however limited, and there is hitherto no research on how neighbourhood greenness impacts the time spent active in green areas. In general, specific research on late middle-aged adults is relatively uncommon (especially in Europe) and does often not include objective measures of PA (Berke et al., 2007; Kaczynski et al., 2008; Lovasi et al., 2008; Shigematsu et al., 2009; Frank et al., 2010; McMorris et al., 2015) or shows inconsistent results (Berke et al., 2007; Lovasi et al., 2008; Frank et al., 2010; King et al., 2011; Carlson et al., 2012; Van Holle et al., 2014). To our knowledge, research on the influence of personal characteristics and neighbourhood greenness on the association between greenness, location and PA in late middle-aged adults in Europe is unprecedented. We also feel that the use of detailed GPS and accelerometer data in this line of research can offer new insights. The main goal of this study is to reach an understanding where late middle-aged adults are mostly physically active in terms of location and in relation to greenness. Secondly, the influence of several individual characteristics, such as gender, working status, body mass index (BMI) and diploma as well as neighbourhood greenness has been studied with respect to PA and its association with greenness and location.

\section{Materials and Methods}

\section{Participants and procedures}

We used data from 180 community-dwelling late middle-aged adults selected from a systematic random sample. Participants were all between 59 and 65 years old, working or retired, and living in Ghent, a mediumsized city (156.2 km²-250,000 inhabitants) (Stad Gent, 2014) in Belgium. In order to participate, individuals had to meet three criteria: i) understand and speak Dutch; ii) live independently; and iii) be able to walk a couple of hundred meters without severe physical restrictions. The home address for each participant was available. They were all visited at home and asked to wear a GPS device (Qstarz BT-Q1000X; Qstarz International, Taipei, Taiwan) and an accelerometer (Actigraph GT3X, GT3X+, or GT1M; ActiGraph, Fort Walton Beach, FL, USA), a valid and reliable tool for objectively measuring PA levels (Melanson and Freedson, 1995; Copeland and Esliger, 2009; Pruitt et al., 2010). The instruments were worn at waist height for a week. The participants entered the required information on PA for different purposes (home, work, transport, recreation) in the international PA questionnaire (i.e., the long past seven days version; IPAQ, 2014). They also provided information regarding several personal characteristics: gender, working status, height and weight (from which the BMI was calculated), and diploma.

\section{Data collection and analysis}

\section{Global positioning system and accelerometer data}

GPS and accelerometer data were captured during the participants' waking hours. GPS data were collected at a 15 -second time interval, between February $22^{\text {nd }} 2013$ and April $5^{\text {th }} 2013$ resulting in a raw dataset of 5,672,590 points. Additionally, participants were equipped with an accelerometer that showed the number of accelerations per 15 seconds. GPS and accelerometer data were linked using the personal activity and location measurement system (PALMS) (Demchak et al., 2012; PALMS, 2015) enabling us to know the number of accelerometer counts for each GPS point, from which each participant's PA level was calculated based on the Freedson cut-off points (Freedson et al., 1998) as shown in Table 1. Because distinction between car and bike movement (especially in the city centre where they have similar speeds) is difficult, the vehicle PA level was only studied in the first part of the manuscript. In the current study, we only took into account data points where people are either sedentary or active. Data points showing nonwearing time and erroneous ones were omitted from the dataset, resulting in $3,019,491$ valid (wearing) data points (53.2\% of the original dataset).

\section{Location calculation}

For each data point, the network distance to each participant's home address was calculated in ArcGIS 10.0 $0^{\mathrm{TM}}$ using Network Analyst (ESRI, 2011). Based on this distance, the following movement classification was made: i) 0 to $50 \mathrm{~m}$ : at the home location; ii) $51-1000 \mathrm{~m}$ : in the neighbourhood; and iii) >1000 m: outside the neighbourhood.

We used a distance of $50 \mathrm{~m}$ for the home location including the yard, since too little movement can cause noise in the GPS data. A distance 
of 1000 m coincides with a 10-15 minute walk and is internationally used as the neighbourhood boundary (Frank et al., 2005; Oliver et al., 2007; Bauman and Bull, 2007; Lovasi et al., 2008; Boruff et al., 2012).

\section{Greenness calculation}

A 10-m resolution land use map containing 48 classes of the Flanders and Brussels region was used to calculate the greenness of each location using ArcGIS 10.0 $0^{\mathrm{TM}}$ (Van Esch et al., 2011). This map was developed by the Flemish Institute for Technological Research (Vlaams Instituut voor Technologisch Onderzoek, VIT0), Mol, Belgium, and combines the CORINE land cover, detailed parcel data, a biological appreciation map and others. The following land use classes were considered as green: agriculture, grassland, forest, swamp, heath land and coastal dune as well as park, recreation and sport terrains. The other classes were considered as non-green land uses (e.g. residential, commercial, industrial, roads). While a further distinction could be made between e.g. natural/built green areas and commercial/residential nongreen ones, in this exploratory study we made a dichotomist distinction to offer a first view on the association between greenness and PA.

\section{Average values per person}

To analyse the association of greenness and location with PA per person and to study the influence of personal characteristics of this association, the point dataset was summarised to obtain average values per person. The following values were calculated using the administration and management tool pgAdmin ${ }^{\mathrm{TM}}$ (PostgreSQL Global Development Group: https://www.postgresql.org/): hours of PA levels [sedentary, vehicle, light physical activity (LPA), moderate-to-vigorous physical activity (MVPA)] per day, hours in green/non-green areas per day, hours at home/neighbourhood/further per day, hours of PA levels in green/non-green per day, hours of PA levels at home/ neighbourhood/further per day. Only participants with at least 6 hours of valid accelerometer data per day and at least 4 valid days were included in the analyses. As a result, we maintained 138 (76.7\%) participants of the initial 180, with respect to whom full further analyses were done.

\section{Neighbourhood greenness}

The neighbourhood greenness was calculated in a network buffer (only using walkable roads) of $1000 \mathrm{~m}$ around each participant's home location using ArcGIS 10.0 ${ }^{\mathrm{TM}}$ (ESRI, 2011), and expressed as the percentage green land use cells of all cells. Data on the road network (TeleAtlas MultiNet ${ }^{\circledR}$ : http://www.tele-mart.com/teleatlas_multinet. php) was used to define the walkable roads.

\section{Geographical and statistical analyses}

Geographical and visual analyses were performed in QGIS $2.8^{\mathrm{TM}}$ (QGIS Develoment Team, 2015). Statistical analyses were done using SPSS Statistics 22 ${ }^{\mathrm{TM}}$ (IBM Corp., 2013). The association between greenness, location and PA per GPS data point $(n=3,019,491)$ was tested for significance using an independent-samples t-test (after successfully testing the data for normality). The averaged data per person $(n=138)$ were examined by performing a linear regression analysis to study the associations of greenness and location with PA (again, after successfully testing the data for normality). To examine whether these associations are similar in different socio-demographic subgroup, stratified linear regression analyses were conducted.

\section{Results}

This section first presents some general descriptive statistics about the population sample. The second part describes analyses of the $3,019,491$ valid data points to detect where the late middle-aged adults $(n=180)$ are mostly active. The third part deals with the analyses based on the data per person $(n=138)$ and has to do with the association between greenness, the distance from home and PA level per person and includes an analysis of the influence of several personal characteristics and neighbourhood greenness.

\section{General descriptive statistics}

General descriptive statistics of the 180 participants are presented in Table 2. The majority of the sample was non-smoking, had a higher education, was retired and had a partner. The mean age was 61.7 years and the mean BMI was 26.0. The sample contains slightly more women than men. From all valid data points $(n=3,019,491)$ it is clear that the participants were mainly sedentary (65.5\%), followed by LPA $(24.0 \%)$, vehicle (5.8\%) and MVPA (4.7\%). Table 3 shows the distribution of valid data points for both greenness and location. The data points referring to the participants' whereabouts mainly pointed at non-green land use classes (residential, commercial, or other industrial) compared to green land use classes (forest, recreation, park, grassland, agriculture). Additionally, it was found that late middle-aged adults spent most of their time at the home location rather than anywhere else.

\section{Where are late middle-aged adults mostly active?}

\section{Geographical and visual analyses}

In Figure 1, data points from one specific green area as an example (the Citadel park) are visualised for all participants, indicating the PA level. One can see that in this green area MVPA (probably mainly walking) was done along the walking trails. At certain locations, we observed some LPA and sedentary behaviour as well, mainly near certain points of interest (in the Southwest a statue with benches, in the Northeast a pond with benches). This type of pattern was also observed at other green locations.

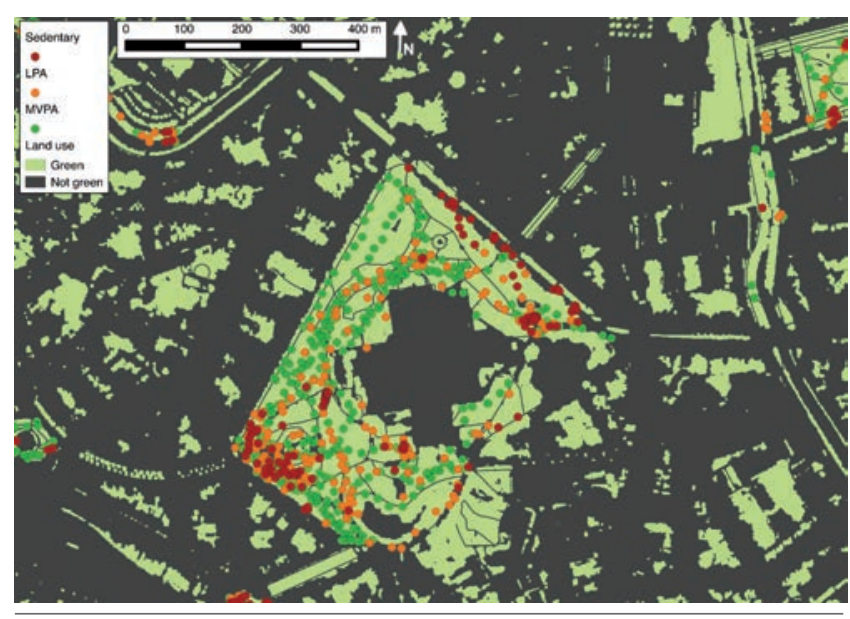

Figure 1. Visualisation of the collected global positioning system and accelerometer data in a green area (Citadel Park in Ghent, Belgium). The figure includes all participants and indicates the physical activity level for sedentary, light physical activity and moderate-to-vigorous physical activity per data point. 
Associations of greenness, location and physical activity per data point

Figure 2 visualises the PA levels depending on the location and greenness of the data points, summed to $100 \%$ for greenness. We did not consider the home location ( $>50 \mathrm{~m}$ ) here, since this is a mainly non-green area, where this analysis would be purposeless. In the neighbourhood, the participants were mainly sedentary and performed LPA. Outside the neighbourhood we observed less sedentary behaviour $(\mathrm{P}<0.05)$ in favour of more time spent in the vehicle $(\mathrm{P}<0.001)$ and more MVPA $(\mathrm{P}<0.001)$. LPA was approximately the same in the neighbourhood and further, and mainly involved walking at a slow pace.

Taking greenness into account, sedentary time was found to be much higher in non-green areas than in green areas $(\mathrm{P}<0.01)$. There is generally more vehicle use $(\mathrm{P}<0.01)$ in green areas, because green areas are often located outside city centres and car use is higher there. LPA $(\mathrm{P}<0.05)$ but more striking MPVA $(\mathrm{P}<0.001)$ was significantly higher in green areas than in non-green areas.

\section{Individual greenness/location/physical activity asso- ciation and the influence of personal characteristics and neighbourhood greenness}

\section{Descriptive statistics}

Table 4 shows some additional general descriptive statistics of the participants $(n=138)$, concerning greenness, location and PA. Each participant had an average of 12.0 hours of data per day (non-wearing time and sleeping excluded) for on average 6.6 days. Only 30 minutes per day was spent in green areas, 6.7 hours were spent at the home location, almost 2 hours in the neighbourhood and more than 3 hours further away (the histogram of the time spent further away shows a large peak between from 1 to 5 hours, and a smaller peak from 6 to 9 hours). Almost 8 hours were spent being sedentary, and approximately 2.8 hours per day were spent being active (LPA and MVPA).

The results indicate that $70 \%$ of the late middle-aged adults are sedentary for more than 7 hours per day and 35\% does not reach the 21.4 minutes of MVPA per day (or 150 minutes per week) to benefit positive health effects.

\section{Associations of greenness, location and physical activity per person}

We performed a linear regression analysis to study the association of greenness and location (i.e. being at home) with PA and found some significant results (Table 5). More time spent in non-green areas was associated with more hours of sedentary behaviour and LPA, while more time in green areas was associated with less sedentary behaviour and more hours of MVPA. More time spent at home was also associated with more sedentary behaviour and LPA.

\section{Influence of personal characteristics and neighbourhood greenness}

Table 6 shows whether the association of greenness and location with PA differs depending on various personal characteristics (gender, working status, BMI, and educational level).

The positive associations between time spent in non-green areas and time being sedentary or in LPA were comparable for the different subgroups. The association between time spent in non-green areas and time in MVPA was positive for males, i.e. more time spent in non-green areas was related to more MVPA, and negative for females, i.e. more time in non-green was related to less MVPA. The negative association between time spent in green areas and sedentary time was only significant for male, retired participants with a normal BMI and lower education. The positive association between time spent in green areas and

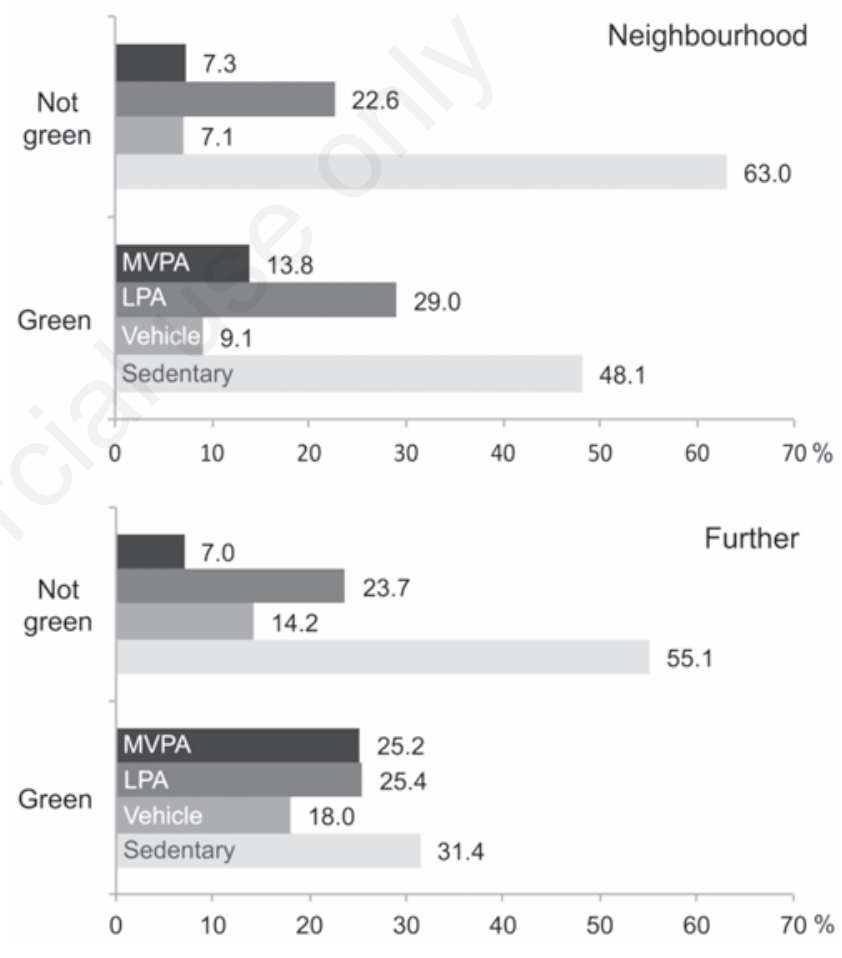

Figure 2. Percentages of the type of physical activity of all valid points depending on greenness and location. Activity types refer to sedentary, vehicle, light physical activity and moderate-to-vigorous physical activity.

Table 1. Accelerometer counts based on estimated physical activities.

\begin{tabular}{lcc} 
Accelerometer data (counts per minute) & Type of defined physical activity & Activity \\
$>60$ & Non-instrument wearing/sleeping & Non-defined; not measured \\
$0-100$ & Sedentary & Reading, watching TV, eating, desk work \\
\hline $0-100($ speed $>5 \mathrm{~km} / \mathrm{h})$ & Vehicle-related & In transport (car/tram etc.); biking \\
$101-1951$ & LPA & $\begin{array}{c}\text { Standing (e.g. ironing, washing up and other } \\
\text { household tasks; low-speed walking) }\end{array}$ \\
\hline $1952-100,000$ & MVPA & Walking, running \\
$>100,000$ & Error $^{\circ}$ & na
\end{tabular}

LPA, light physical activity; MVPA, moderate-to-vigorous physical activity; na, not available. ${ }^{\circ}$ Removed from the dataset. 
LPA was only significant for men, and the association between time spent in green areas and MVPA was the strongest for highly educated people and those living in a green neighbourhood. The positive association between time spent at home and sedentary behaviour was strongest for retired participants. The association between time spent at home and doing LPA is comparable in the different subgroups.

\section{Discussion}

Previous research has shown that being active in green areas has a positive effect both on physical and mental health (Frumkin, 2001; St Leger, 2003; Thompson Coon et al., 2011; Dewulf et al., 2016). This study demonstrates that late middle-aged adults spend an average of 30 minutes per day in green areas, and when more time is spent there, people are more active compared to their behaviour in non-green areas. This suggests that availability of green areas lead to higher amounts of PA. The knowledge of the link between greenness and PA hotspots is important for policy makers wishing to stimulate PA. Nevertheless, there will always be a large proportion of PA occurring in non-green areas (e.g. in city centres). Being physically active in nongreen areas does not necessarily imply a negative health impact, but small green features could be introduced to improve people's wellbeing. However, spending more time at home is associated with more sedentary behaviour, and with more time spent at home with increasing age (Kerr et al., 2012). A vicious circle is established that could thus lead to more sedentary behaviour and related health risks (Clark et al., 2014; Ortlieb et al., 2014). Our results of the influence of various characteristics on the association between greenness, location and PA indicate that the association between the time spent in non-green and MVPA is positive for males and negative for females. This means that more time spent in non-green areas is related to more MVPA for males, while to less MVPA for females. The positive association between the time spent in green areas and MVPA is strongest for highly educated people and for those living in a green neighbourhood, indicating that living in a green neighbourhood leads to more PA when time is spent in green areas, which coincides with the findings by McMorris et al. (2015). In contrast to previous studies (Berke et al., 2007; Frank et al., 2010; King et al., 2011; Marshall et al., 2014; Van Holle et al., 2014; Marquet and Miralles-Guasch 2015), on the other hand, living in a non-green neighbourhood was not found to be associated with more PA and less sedentary behaviour. The positive association between the time spent at home and sedentary behaviour was found to be the strongest for retired participants, indicating that once retired the time spent at home is often linked with sedentary behaviour. It would be interesting to study the association between greenness in the home neighbourhood and PA (and more specifically PA in green areas) further in different age groups. Our study has several strengths compared with similar studies. First, this research is the first to study the association between green- ness, location and PA with respect to late middle-aged adults in Europe. Second, most studies are only based on self-reported PA values (Berke et al., 2007; Lovasi et al., 2008; Kaczynski et al., 2008; Shigematsu et al., 2009; Frank et al., 2010), while we used accelerometer-based PA, which offers more objective values. This made it possible to attribute PA levels to each GPS data point, which cannot be done when using only selfreported data, where for example only binary data (participant walked or did not walk today) is extracted (Clark et al., 2014). Third, the combined use with GPS data offers detailed insights in where active behaviour is done (Duncan et al., 2009; Troped et al., 2010; Oreskovic et al., 2012; Kerr et al., 2012). In contrast to previous studies, where only the home neighbourhood is considered, we additionally gathered information on the specific context of where PA is carried out. Although our approach had also limitations, they open up interesting avenues for future work. First and foremost, we already described the difficulty to detect bicycle use (Hansen et al., 2012) when deriving PA levels from accelerometer data. We considered both bike and car use as vehicle, therefore losing some active data when people are biking. In future work, mode-detection algorithms could be used to detect transport modes. However, for the specific research results reported here, the loss of information must be deemed limited as only $5.8 \%$ of the entire dataset was considered vehicle-related. Second, in this cross-sectional study it was not possible to extract causal relationships. One must therefore be careful when interpreting the results, because it is not given that the greenness of the area is the cause of a higher PA activity. Future studies should focus on longitudinal research to detect whether or not changes are causal, and occasional or persistent. In this way, the

Table 2. General descriptive statistics of the study sample.

\begin{tabular}{lc}
\hline Parameter & Sample $(\mathrm{n}=180)$ \\
Age, mean (CI=5-95\%) & $61.7,(58.0-65.0)$ \\
BMI, mean (Cl=5-95\%) & $26.0,(20.6-32.4)$ \\
\hline Gender (\% male) & 47.8 \\
Smoking (\% not smoking) & 90.0 \\
\hline Working/retired (\% working) & 23.3 \\
Marital status (\%) & \\
Married & 67.8 \\
Living together & 7.8 \\
Single & 4.4 \\
Divorced & 14.4 \\
Widow(er) & 5.6 \\
\hline Education (\%) & \\
Primary school & 7.2 \\
Secondary school & 40.0 \\
Higher/University & 52.2 \\
Missing & 0.6 \\
\hline Cl, confidence interval; BMI, body mass index. &
\end{tabular}

Table 3. Distribution of valid data points with regard to greenness/non-greenness and location.

\begin{tabular}{lccc} 
& Non-green area $(\%)$ & Green area (\%) & Total $(\%)$ \\
Home $(<50 \mathrm{~m})$ & $1,618,459(53.6)$ & $12,931(0.4)$ & $1,631,390(54.0)$ \\
Neighbourhood $(50-1000 \mathrm{~m})$ & $441,267(14.6)$ & $30,605(1.0)$ & $471,872(15.6)$ \\
\hline Further away $(>1000 \mathrm{~m})$ & $852,484(28.2)$ & $63,745(2.1)$ & $916,229(30.3)$ \\
Total & $2,912,210(96.4)$ & $108,281(3.6)$ & $3,019,491(100)$ \\
\hline
\end{tabular}

Total number of points $=3,019,491$. 
effect of introducing green areas (using natural experiments) on PA levels can be studied (Bauman and Bull, 2007). Third, the data were collected in March, possibly influencing space-time activity patterns of some participants because of the weather (e.g. low temperatures, snow). Future research should incorporate weather characteristics (e.g. temperature, rain, wind speed) to account for this. Fourth, future studies on this topic should try to incorporate socio-economic status (e.g. income, education) indicators, to analyse its possible correlation with walkability and greenness and potential influence on the association of greenness, location and PA. Finally, we considered agriculture as a green area. Despite the fact that moving through these areas is associated with positive health effects, this can possibly affect our results since there can also be functional trips. For example people living in a rural neighbourhood are likely to spend more time in green areas because they automatically pass through green areas when moving. This could be reduced in future research by filtering the trips per goal. Related to this final limitation, a more detailed distinction could be made between natural (e.g. forest, coastal dune, grassland) and built

Table 4. Descriptive statistics of the study sample ( $n=138)$ concerning greenness, location, and physical activity.

\begin{tabular}{lc} 
Parameter & Hours per day \\
Valid days & $6.6,(5.0-8.0)$ \\
Data & $12.0,(8.8-14.8)$ \\
\hline Greenness & \\
$\quad$ Non-green & $11.6,(8.4-14.4)$ \\
$\quad$ Green & $0.4,(0.0-1.7)$ \\
Location & \\
Home & $6.7,(0.0-12.0)$ \\
Neighbourhood & $1.8,(0.1-10.3)$ \\
Further & $3.4,(0.6-9.4)$ \\
\hline Physical activity & \\
Sedentary & $7.9,(5.2-10.4)$ \\
Vehicle & $0.6,(0.1-1.3)$ \\
LPA & $2.3,(1.3-3.6)$ \\
MVPA & $0.5,(0.1-1.3)$ \\
\hline
\end{tabular}

LPA, light physical activity; MVPA, moderate-to-vigorous physical activity. Values are expressed as mean (confidence interval=5-95\%). green areas (e.g. park, sport terrain), in future work considering the possibility that they could be differently related to PA.

\section{Conclusions}

The combined use of GPS and accelerometer data can help to detect where people are sedentary or physically active. Knowing where older people are mainly physically active should encourage policy makers to increase activity in this age cohort. Despite the fact that the observed population spends little time in green areas, higher levels of PA are reached in green areas. As this is the first research studying the association between greenness, location and PA, and considering the influence of several characteristics on this relationship, our results are useful in updating the current knowledge on PA in late middle-aged adults. However, more research is needed to better understand where and why late middle-aged adults are physically active or sedentary.

Table 5. Results of linear regression analysis among greenness, location and physical activity.

\begin{tabular}{llc}
\hline Independent variable & Dependent variable & $\beta^{\circ}$ \\
Hours in non-green area & Hours of sedentary behaviour & $0.80^{* * *}$ \\
& Hours of LPA & $0.47^{* * *}$ \\
& Hours of MVPA & 0.10 \\
Hours in green area & Hours of sedentary behaviour & $-0.16^{*}$ \\
& Hours of LPA & 0.02 \\
& Hours of MVPA & $0.17^{*}$ \\
\hline Hours at home & Hours of sedentary behaviour & $0.33^{* * *}$ \\
& Hours of LPA & $0.37^{* * *}$ \\
& Hours of MVPA & 0.03 \\
\hline
\end{tabular}

LPA, light physical activity; MVPA, moderate-to-vigorous physical activity. ${ }^{*} \mathrm{P}<0.05 ;{ }^{* * *} \mathrm{P}<0.001$. ${ }^{\circ}$ Standardized regression coefficient.

Table 6. Results of the stratified linear regression analysis.

\begin{tabular}{|c|c|c|c|c|c|c|c|c|c|c|c|}
\hline \multirow{2}{*}{$\begin{array}{l}\text { Independent } \\
\text { variable }\end{array}$} & \multirow{2}{*}{$\begin{array}{l}\text { Dependent } \\
\text { variable }^{\circ}\end{array}$} & \multicolumn{2}{|c|}{ Gender } & \multicolumn{2}{|c|}{ Working status } & \multicolumn{2}{|c|}{ BMI } & \multicolumn{2}{|c|}{ Diploma } & \multicolumn{2}{|c|}{ Neighbourhood greenness } \\
\hline & & Bmale & Bfemale & Bretired & Bworking & Bnormal & Bhigh & Blow & Bhigh & Bnot & Bgreen \\
\hline \multirow[t]{3}{*}{ Non-green } & Sedentary & $0.86 * * *$ & $0.73^{* * *}$ & $0.82^{* * *}$ & $0.70^{* * *}$ & $0.78^{* * *}$ & $0.82 * * *$ & $0.79 * * *$ & $0.84^{* * *}$ & $0.81^{* * *}$ & $0.75^{* * *}$ \\
\hline & $\mathrm{LPA}^{\#}$ & $0.50 * * *$ & $0.52^{* * *}$ & $0.48^{* * *}$ & $0.46^{* *}$ & $0.44^{* *}$ & $0.50^{* * *}$ & $0.56^{* * *}$ & $0.41^{* * *}$ & $0.48 * * *$ & $0.46^{* * *}$ \\
\hline & $\mathrm{MVPA}^{\S}$ & $0.31^{* *}$ & $-0.27 *$ & 0.13 & -0.06 & 0.01 & 0.17 & 0.11 & 0.07 & 0.07 & 0.18 \\
\hline \multirow[t]{3}{*}{ Green } & $\begin{array}{l}\text { Sedentary } \\
\text { behaviour }\end{array}$ & $-0.20^{*}$ & -0.14 & $-0.22 *$ & 0.64 & $-0.30^{*}$ & -0.03 & $-0.36^{* *}$ & 0.05 & -0.18 & -0.03 \\
\hline & $\mathrm{LPA}^{\#}$ & $0.24^{* *}$ & -0.13 & 0.04 & -0.06 & -0.17 & 0.16 & -0.04 & 0.06 & 0.01 & 0.09 \\
\hline & MVPA $^{\S}$ & $0.26^{*}$ & $0.15^{*}$ & $0.19 *$ & $0.14^{*}$ & $0.23^{*}$ & $0.14^{*}$ & $0.10^{*}$ & $0.30^{* *}$ & 0.07 & $0.31^{* *}$ \\
\hline \multirow[t]{3}{*}{ At home } & $\begin{array}{l}\text { Sedentary } \\
\text { behaviour }\end{array}$ & $0.30 * *$ & $0.37^{* *}$ & $0.50^{* * *}$ & -0.23 & $0.28 *$ & $0.38 * *$ & $0.45^{* * *}$ & $0.24 *$ & $0.40^{* *}$ & $0.24^{*}$ \\
\hline & $\mathrm{LPA}^{\#}$ & $0.36 * *$ & $0.38 * * *$ & $0.40 * * *$ & $0.36 *$ & $0.41^{* *}$ & $0.35^{* *}$ & $0.34^{* *}$ & $0.42 * * *$ & $0.36 * *$ & $0.35^{* *}$ \\
\hline & $\mathrm{MVPA}^{\S}$ & -0.10 & 0.14 & 0.02 & 0.08 & 0.04 & 0.03 & 0.04 & 0.04 & 0.08 & -0.00 \\
\hline
\end{tabular}

BMI, body mass index; LPA, light physical activity; MVPA, moderate-to-vigorous physical activity. ${ }^{\circ}$ Hours in/of; $"$ light physical activity; ${ }^{3}$ moderate-to-vigorous physical activity. ${ }^{*} \mathrm{P}<0.05 ;{ }^{* *} \mathrm{P}<0.01 ;{ }^{* * * P}<0.001$. 


\section{References}

Almanza E, Jerrett M, Dunton G, Seto E, Pentz MA, 2012. A study of community design, greenness, and physical activity in children using satellite, GPS and accelerometer data. Health Place 18:46-54.

Banister D, Bowling A, 2004. Quality of life for the elderly: the transport dimension. Trans Policy 11:105-15.

Bauman AE, Bull FC, 2007. Environmental correlates of physical activity and walking in adults and children: a review of reviews. Am J Public Health 44:1-44.

Bekö G, Kjeldsen BU, Olsen Y, Schipperijn J, Wierzbicka A, Karottki DG, Toftum J, Loft S, Clausen G, 2015. Contribution of various microenvironments to the daily personal exposure to ultrafine particles: personal monitoring coupled with GPS tracking. Atmos Environ 110:122-9.

Berke EM, Koepsell TD, Moudon AV, Hoskins RE, Larson EB, 2007. Association of the built environment with physical activity and obesity in older persons. Am J Public Health 97:486-92.

Boruff BJ, Nathan A, Nijënstein S, 2012. Using GPS technology to (re)examine operational definitions of 'neighbourhood' in place-based health research. Int J Health Geogr 11:22.

Carlson JA, Sallis JF, Conway TL, Saelens BE, Frank LD, Kerr J, Cain KL, King AC, 2012. Interactions between psychosocial and built environment factors in explaining older adults' physical activity. Prev Med 54:68-73.

Cavill N, Kahlmeier S, Rutter H, Racioppi F, Oja P, 2008. Economic analyses of transport infrastructure and policies including health effects related to cycling and walking: a systematic review. Transp Policy 15:291-304.

Centers for Disease and Control Prevention, 1996. Physical activity and health: a report of the surgeon general. Centers for Disease and Control Prevention, Atlanta, GA, USA.

Clark AF, Scott DM, Yiannakoulias N, 2014. Examining the relationship between active travel, weather, and the built environment: a multilevel approach using a GPS-enhanced dataset. Transportation 41:325-38.

Coombes E, Van Sluijs E, Jones A, 2013. Is environmental setting associated with the intensity and duration of children's physical activity? Findings from the SPEEDY GPS study. Health Place 20:62-5.

Copeland JL, Esliger DW, 2009. Accelerometer assessment of physical activity in active, healthy older adults. J Aging Phys Activ 17:17-30.

Demchak B, Kerr J, Raab F, Patrick K, Krüger I, 2012. PALMS: a modern coevolution of community and computing - using policy driven development. Proc HICSS 2012:2735-44.

Department of Health, 2004. At least five a week: evidence on the impact of physical activity and its relationship to health. Available from: http://webarchive.nationalarchives.gov.uk/+/ dh.gov.uk/en/publicationsandstatistics/publications/publicationspolicyandguidance/dh_4080994

Dewulf B, Neutens T, Van Dyck D, De Bourdeaudhuij I, Panis L, De Weerdt Y, Van de Weghe N, 2016. Dynamic assessment of inhaled air pollution using GPS and accelerometer data. J Trans Health 15:14.

Dons E, Temmerman P, Van Poppel M, Bellemans T, Wets G, Int Panis L, 2013. Street characteristics and traffic factors determining road users' exposure to black carbon. Sci Total Environ 447:72-9.

Duncan MJ, Badland HM, Mummery WK, 2009. Applying GPS to enhance understanding of transport-related physical activity. J Sci Med Sport 12:549-56.

Elgethun K, Fenske RA, Yost MG, Palcisko GJ, 2003. Time-location analysis for exposure assessment studies of children using a novel global positioning system instrument. Child Health 111:115-22.

ESRI, 2011. AcrGIS desktop. Environmental Systems Research Institute, Redlands, CA, USA.

Fan Y, Das KV, Chen Q, 2011. Neighborhood green, social support, physical activity, and stress: assessing the cumulative impact. Health Place 17:1202-11.

Frank LD, Kerr J, Rosenberg D, King AC, 2010. Healthy aging and where you live: community design relationships with physical activity and body weight in older Americans. J Phys Act Health 7(Suppl.1):8290.

Frank LD, Schmid TL, Sallis JF, Chapman J, Saelens BE, 2005. Linking objectively measured physical activity with objectively measured urban form: findings from SMARTRAQ. Am J Prev Med 28:117-25.

Freedson PS, Melanson E, Sirard J, 1998. Calibration of the computer science and applications, Inc. accelerometer. Med Sci Sports Exer 30:777-81.

Frumkin H, 2001. Beyond toxicity: human health and the natural environment. Am J Prev Med 20:234-40.

Hamilton MT, Healy GN, Dunstan DW, Theodore W, Owen N, 2012. Too little exercise and too much sitting: inactivity physiology and the need for new recommendations on sedentary behavior. Curr Cardiovasc Risk Rep 2:292-8.

Hansen BH, Kolle E, Dyrstad SM, Holme I, Anderssen SA, 2012. Accelerometer-determined physical activity in adults and older people. Med Sci Sports Exer 44:266-72.

IBM Corp, 2013. IBM SPSS statistics. IBM Corp., Armonk, NY, USA.

Int Panis L, de Geus B, Vandenbulcke G, Willems H, Degraeuwe B, Bleux N, Mishra V, Thomas I, Meeusen R, 2010. Exposure to particulate matter in traffic: a comparison of cyclists and car passengers. Atmos Environ 44:2263-70.

IPAQ, 2014. International physical activity questionnaire. Available from: http://www.ipaq.ki.se

Kaczynski AT, Potwarka LR, Saelens BE, 2008. Association of park size, distance, and features with physical activity in neighborhood parks. Inn Design Anal 98:1451-6.

Kerr J, Marshall S, Godbole S, Neukam S, Crist K, Wasilenko K, Golshan S, Buchner D, 2012. The relationship between outdoor activity and health in older adults using GPS. Int J Environ Res Public Health 9:4615-25.

King AC, Guralnik JM, 2010. Maximizing the potential of an aging population. Am Med Assoc 304:1944-5.

King AC, Sallis JF, Frank LD, Saelens BE, Cain K, Conway TL, Chapman JE, Ahn DK, Kerr J, 2011. Aging in neighborhoods differing in walkability and income: associations with physical activity and obesity in older adults. Soc Sci Med 73:1525-33.

Lachowycz K, Jones AP, Page AS, Wheeler BW, Cooper AR, 2012. What can global positioning systems tell us about the contribution of different types of urban greenspace to children's physical activity? Health Place 18:586-94.

Landi F, Abbatecola AM, Provinciali M, Corsonello A, Bustacchini S, Manigrasso L, Cherubini A, Bernabei R, Lattanzio F, 2010. Moving against frailty: does physical activity matter? Biogerontology 11:537-45.

Lovasi GS, Moudon AV, Pearson AL, Hurvitz PM, Larson EB, Siscovick DS, Berke EM, Lumley T, Psaty BM, 2008. Using built environment characteristics to predict walking for exercise. Int J Health Geogr $7: 10$.

Mackay GJ, Neill JT, 2010. The effect of 'green exercise' on state anxiety and the role of exercise duration, intensity, and greenness: a quasi-experimental study. Psychol Sport Exer 11:238-45. 
Marquet 0, Miralles-Guasch C, 2015. Neighbourhood vitality and physical activity among the elderly: the role of walkable environments on active ageing in Barcelona, Spain. Soc Sci Med 135:24-30.

Marshall WE, Piatkowski DP, Garrick NW, 2014. Community design, street networks, and public health. J Trans Health 1:1-15.

McMorris 0, Villeneuve PJ, Su J, Jerrett M, 2015. Urban greenness and physical activity in a national survey of Canadians. Environ Res 137:94-100.

Melanson E, Freedson PS, 1995. Validity of the computer science and applications, Inc. (CSA) activity monitor. Med Sci Sports Ex 27:93440.

Oliver LN, Schuurman N, Hall AW, 2007. Comparing circular and network buffers to examine the influence of land use on walking for leisure and errands. Int J Health Geogr 6:41.

Oreskovic NM, Blossom J, Field AE, Chiang SR, Jonathan P, 2012. Combining global positioning system and accelerometer data to determine the locations of physical activity in children. Geospat Health 6:263-72.

OECD, 2006. Study projects growing pressure on public health spending over and above effects of ageing society. Organization for Economic Cooperation and Development, Paris, France.

Ortlieb S, Dias A, Gorzelniak L, Nowak D, Karrasch S, Peters A, Kuhn KA, Horsch A, Schulz H, 2014. Exploring patterns of accelerometryassessed physical activity in elderly people. Int J Behav Nutr P A 11:28.

PALMS, 2015. Physical activity and location measurement. Available from: https://ucsd-palms-project.wikispaces.com

Pruitt LA, Ph D, Glynn NW, King AC, Guralnik JM, Aiken EK, Miller G, Haskell WL, 2010. Use of accelerometry to measure physical activity in older adults at risk for mobility disability. J Aging Phys Acta 16:416-34.

Rockwood K, Howlett SE, MacKnight C, Beattie BL, Bergman H, Hebert R, Hogan DB, Wolfson C, McDowell I, 2004. Prevalence, attributes, and outcomes of fitness and frailty in community-dwelling older adults: report from the canadian study of health and aging. $\mathrm{J}$ Gerontol A 59:1310-7.

Seeger CJ, Welk GJ, Erickson S, 2007. Using global position systems (GPS) and physical activity monitors to assess the built environment data-collection devices and processes. URISA J 2005:5-12.

Shigematsu R, Sallis JF, Conway TL, Saelens BE, Frank LD, Cain KL, Chapman JE, King AC, 2009. Age differences in the relation of perceived neighborhood environment to walking. Med Sci Sport Exer
41:314-21.

St Leger L, 2003. Health and nature: new challenges for health promotion. Health Promot Int 18:173-5.

Stad Gent, 2014. Bevolking. Available from: https://stad.gent/

Sugiyama T, Leslie E, Giles-Corti B, Owen N, 2008. Associations of neighbourhood greenness with physical and mental health: do walking, social coherence and local social interaction explain the relationships? J Epidemiol Comm Health 62:e9.

Thompson Coon J, Boddy K, Stein K, Whear R, Barton J, Depledge MH, 2011. Does participating in physical activity in outdoor natural environments have a greater effect on physical and mental wellbeing than physical activity indoors? A systematic review. Environ Sci Technol 45:1761-72.

Troiano RP, Berrigan D, Dodd KW, Mâsse LC, Tilert T, McDowell M, 2008. Physical activity in the United States measured by accelerometer. Med Sci Sport Exer 40:181-8.

Troped PJ, Wilson JS, Matthews CE, Cromley EK, Melly SJ, 2010. The built environment and location-based physical activity. Am J Prev Med 38:429-38.

US Department of Health and Human Services, 2008. Physical activity guidelines advisory committee report. US Department of Health and Human Services, Washington, DC, USA.

Van Cauwenberg J, De Bourdeaudhuij I, De Meester F, Van Dyck D, Salmon J, Clarys P, Deforche B, 2011. Relationship between the physical environment and physical activity in older adults: a systematic review. Health Place 17:458-69.

Van Esch L, Poelmans L, Engelen G, Uljee I, 2011. Landgebruikskaart Vlaanderen en Brussel. VITO, Mol, Belgium.

Van Holle V, Deforche B, Van Cauwenberg J, Goubert L, Maes L, Van de Weghe N, De Bourdeaudhuij I, 2012. Relationship between the physical environment and different domains of physical activity in european adults: a systematic review. BMC Public Health 12:1-48.

Van Holle V, Van Cauwenberg J, Van Dyck D, Deforche B, Van de Weghe N, De Bourdeaudhuij I, 2014. Relationship between neighborhood walkability and older adults' physical activity: results from the belgian environmental physical activity study in seniors (BEPAS Seniors). Int J Behav Nut P A 11:110.

Warburton DER, Nicol CW, Bredin SSD, 2006. Health benefits of physical activity: the evidence. Can Med Ass J 174:801-9.

WHO, 2010. Global recommendations on physical activity for health. World Health Organization, Geneva, Switzerland. 